\title{
QUE NÃO SEJA O ESMALTE MAIS QUE O OURO. Teoria do discurso histórico no pensamento de D. Francisco Manuel de Melo
}

\author{
Bruno Martins Boto Leite*
}

\begin{abstract}
RESUMO: O estudo da escrita da história do fidalgo português Francisco Manuel de Melo (16061666) foi objeto de muitos trabalhos de estudiosos da história e da literatura da época moderna ibérica. Contudo, a maioria destes estudos fundaram-se numa reflexão que não seguiu a exigência da análise iuxta propria principia: com base na análise das obras históricas do fidalgo foram elaboradas leituras externas ao tempo de produção da historiografia do intelectual português. Acometidos por uma preocupação filológica, pretendemos, neste artigo, analisar a teoria do discurso histórico de Francisco Manuel de Melo presente na obra de crítica literária, o Hospital das Letras, buscando com isso compreender as categorias empregadas pelo próprio autor na produção de seus escritos históricos.

PALAVRAS-CHAVE: Historiografia da Época Moderna; Teoria da História; Humanismo português; Cultura e Poder.
\end{abstract}

\section{Que não seja o esmalte mais que o ouro - Theory of historical discourse in the thought of D. Francisco Manuel de Melo.}

ABSTRACT: The study of the historiography of the noble Portuguese noble Francisco Manuel de Melo (1606-1666) was the object of many studies by history and literature researchers of the Iberian Peninsula in the early modern period. However, most of these studies were based on a reflection that did not follow the requirement of an analysis iuxta propria principia: based on the analysis of the historical work of the nobleman we find readings external to the time of production of the historiography of the Portuguese intellectual. Affected by a philological concern, we intend, in this article, to analyze the theory of historical discourse of Francisco Manuel de Melo present in the work of literary criticism, Hospital das Letras, seeking to understand the categories used by the author himself in the production of his historical writings.

KEYWORDS: Early-Modern Historiography; Theory of History; Portuguese Humanism; Culture and Power.

\section{Que não seja o esmalte mais que o ouro - Teoría del discurso histórico de D. Francisco Manuel de Melo.}

RESUMEN: El estudio de la escritura de la historia del noble portugués Francisco Manuel de Melo (1606-1666) ha sido objeto de muchas obras de estudiosos de la historia y de la literatura de la era moderna ibérica. Sin embargo, la mayoría de estos estudios se basaron en una reflexión que no siguió el requisito de un análisis iuxta propio principia: basándose en el análisis de las obras históricas del hidalgo se prepararon lecturas externas al momento de la producción de la historiografía del intelectual portugués. Capturados por una preocupación filológica, pretendemos, en este artículo, analizar la teoría del discurso histórico de Francisco Manuel de Melo presente en la obra de crítica literaria, el Hospital das Letras, buscando con ello comprender las categorías empleadas por el propio autor en la producción de sus escritos históricos.

PALABRAS CLAVE: Historiografía de la época moderna; Teoría de la Historia; Humanismo portugués; Cultura y poder.

\footnotetext{
*Doutor em história pelo Istituto Universitario Europeo de Florença, Itália (2012). Atualmente é professor de "História Moderna" na Universidade Federal Rural de Pernambuco - UFRPE. Contato: Universidade Federal Rural de Pernambuco, Departamento de História, Rua Dom Manuel de Medeiros, s/n, Dois Irmãos, CEP: 52171900, Recife, PE, Brasil. E-mail:impetusfaciens@ gmail.com. ORCID: http://orcid.org/0000-0003-2307-4005.
} 
O fidalgo diplomata e político português, Francisco Manuel de Melo (1606-1666), importante personagem presente em muitos processos políticos vividos em Portugal no século XVII, representa um dos altos expoentes da literatura barroca e do pensamento historiográfico português do período moderno. Na tão conhecida obra História da literatura portuguesa de autoria de Antônio José Saraiva e Oscar Lopes, manual de história da literatura dirigido aos jovens nas escolas portuguesas, Melo era colocado ao lado do padre Antônio Vieira como uma das duas maiores figuras da literatura portuguesa do Barroco. Sobre ele, Saraiva e Lopes diziam que:

[Melo] é, em Portugal a personificação mais acabada da cultura aristocrática peninsular na época da Restauração. (...) Não é apenas pela sua larga experiência que D. Francisco Manuel se pode considerar típico representante da sua classe na época, pois o seu legado literário permite classificá-lo como um dos polígrafos peninsulares que mais variadas facetas apresentam a exame. ${ }^{1}$

Melo representaria, ao contrário de Vieira, que personificaria a tradição eclesiástica, o aspecto mais aristocrático da tradição barroca portuguesa. Sua importância residiria, portanto, no bel-letrismo de sua escrita romanesca e poética e em sua versatilidade literária: donde a classificação do letrado barroco pelo crítico como um polígrafo. No que tocaria a escrita histórica, por outro lado, Saraiva afirmava que:

D. Francisco não tinha, provavelmente, nem temperamento nem condições para uma historiografia de fôlego. Nas Epanáforas, a precisão dos dados geográficos e onomásticos deixa a desejar, e a história do suposto primeiro descobrimento da Madeira, embora baseada num relato autêntico de Francisco Alcoforado, escudeiro do infante D. Henrique, interessa principalmente como um romance sentimental de escola bernardiana. ${ }^{2}$

Isto dito, segundo a compreensão tradicional da produção historiográfica de Francisco Manuel de Melo, o fidalgo seria, antes de qualquer coisa, um bom escritor/poeta e não um bom historiador. E sua historiografia se mostraria como um desdobramento da arte da retórica, baseada mais na beleza do discurso do que no rigor do método e na veracidade das informações ali dispostas. Afirmação que, na verdade, para muitos estudiosos do tema aparentou óbvia, tendo em vista que o desenvolvimento da diplomática pelo beneditino de Saint-Maur, Jean Mabillon, na polêmica contra os jesuítas bolandistas, escritores da Acta Sanctorum, só teria lugar no final do século $\mathrm{XVII}^{3}$ e não antes disso.

Donde poderíamos afirmar que, até esse importante momento da crítica historiográfica, a escrita da história estaria contida na arte da palavra e da eloquência, na retórica, e não se apresentaria como um conhecimento autônomo e com regras próprias, 
internas, como se apresentará a partir do final do século XVII e, mais precisamente, no século XVIII. A história, desde a antiguidade até finais do século XVII, apresentou-se, portanto, como uma Ars. Foi somente com o desenvolvimento de uma crítica no final do século em questão, como dissemos, que a história se teria libertado desta sua forma anterior para constituir-se em novo paradigma, mais crítico, e, então, dispor-se como uma Scientia.

Contudo, é preciso lembrar, que apesar do caráter artístico e aparentemente livre da composição histórica antes do desenvolvimento de técnicas mais críticas e mediadas de análise, o conhecimento histórico, a Ars historica, já apresentava determinadas formas e regras de composição e tratamento dos indícios que a tornavam, senão uma ciência autônoma, ao menos um gênero bastante singular ${ }^{4}$.

Donde a compreensão de Francisco Manuel de Melo como um exímio escritor e um bel-letrista não tirou dos historiadores mais recentes o interesse em estudar os escritos históricos do fidalgo como importantes documentos para o estudo da história da península ibérica do período moderno. Suas obras históricas mais conhecidas versavam sobre temas e eventos importantes deste passado. Dentre elas, a mais conhecida e comentada, a Historia de los movimientos y separación de Cataluña, onde narra os acontecimentos da Revolta da Catalunha de 1640, resultado da presença indesejada de tropas estrangeiras na região, é tida como a obra prima do gênero de autoria do escritor português. Nesta obra, como em poucas da época, Melo traria aos leitores do presente informações e descrições importantes sobre a guerra em questão.

Além deste escrito histórico, tão lido e estudado por historiadores ibéricos contemporâneos, Francisco Manuel deixou-nos outras importantes obras históricas sobre o universo político e militar português da época moderna que tiveram impacto nos estudos históricos do período. Entre essas muitas obras, destacam-se o El mayor pequeno. Vida y muerte del Serafim humano Francisco de Assis (1647), o El fenis de Africa, Augustino Aurelio, Obispo Hipponense (1648), as Epanaphoras de varia historia portuguesa (1660) e a grande obra que permaneceu manuscrita até ser publicada postumamente em 1944, o Tácito português. Vida, morte, feytos e dictos de el Rey Dom João o IV de Portugal.

As Epanaphoras de varia historia portuguesa merecem um destaque nessa produção pelo impacto que produziram e pela importância que tiveram para os estudos mais recentes da história portuguesa da época moderna. Composta por cinco relatos ou epanáforas neologismo grego inventado por Melo para designar um relato histórico sobre um tema 
circunscrito, monográfico -, a obra versava sobre temas candentes da política portuguesa da época.

Em cinco relatos, Melo narrava muitas pequenas histórias do interesse dos nobres portugueses envolvidos em assuntos de Estado. As epanáforas política, trágica, amorosa, bélica e triunfante diziam respeito, respectivamente, à narrativa da revolta popular, fiscal, que teve lugar em Évora em 1637, àquela do naufrágio da armada portuguesa na França em 1627, àquela do descobrimento da Ilha da Madeira em 1420, àquela do conflito do Canal de Inglaterra entre as armas espanholas e holandesas em 1639 e, finalmente, àquela da restauração de Pernambuco dos invasores holandeses em 1654.

Dentre esses relatos, especial destaque merece ser dado às Alterações de Évora, isso porque ao tratar da política tirânica do Conde Duque de Olivares que teve por consequência alterar a harmonia política de Portugal, Melo traz ao leitor do presente as ações e o protagonismo de grupos bastante negligenciados pela cultura e sociedade da época. Como nos romances picarescos espanhóis, a pena de Melo trazia à luz a presença de grupos sociais sem voz nos relatos históricos de então, ainda que essa aparição, no pensamento do fidalgo, somente se apresentasse como uma consequência natural, como um espasmo, de uma má ação de governo. Má ação, essa, que era vista como desastre ou hecatombe, coisa a ser evitada pelo bom governo ${ }^{5}$. O livro, assim, além de ilustrar um certo protagonismo dos grupos populares servia como um manual de prudência política.

Apesar do modo de narrar a revolta, poucos historiadores de sua época deram tanto relevo e importância às respostas populares às medidas de governo pouco razoáveis empreendidas por ministros do período, como aquelas do tirânico Conde-Duque de Olivares. Por isso, o vasto acesso à obra de Melo intensificou-se nas décadas de 60-70 do século XX, quando o interesse pelo protagonismo popular e pelo estudo dos levantes camponeses e artesãos levou muitos historiadores - muitos dos quais marxistas - a ver na obra do fidalgo como um importante instrumento de estudo da atuação política das camadas sociais menos favorecidas em Portugal.

O tema da guerra, das revoltas, da vida nas cortes e a vida de grandes heróis da política portuguesa eram os temas privilegiados pela pena do sábio fidalgo, lugar corrente nos textos de Melo. Seu estudo projeta-se, portanto, com importância na compreensão de temas relativos à história ibérica e ao Estado Espanhol e Português do período moderno.

Os estudos mais recentes da historiografia do fidalgo português, visando compreender seu método histórico e seu pensamento político, foram empreendidos por 
diversos autores, precisamente, com base no estudo de seus escritos históricos. A maioria desses estudos, é preciso dizer, surge em contextos analíticos bastante específicos: muitos dos quais vinham inseridos no campo da literatura. Estes estudos tenderam a organizar a produção escrita do fidalgo de acordo com uma convenção imposta por uma história da literatura portuguesa ou espanhola que buscou classificar e compreender a produção do personagem levando em conta, antes qualquer coisa, as características técnicas e estilísticas de sua escrita e não a sua inserção e relevância histórica. A questão de se utilizar os escritos de Melo como elementos ou indícios de uma reflexão sobre o passado político ibérico estava fora da preocupação de muitos estudiosos.

O indício maior desta afirmação é o fato de que parte importante das edições de suas obras publicadas recentemente, mais precisamente nos séculos XX e XXI, achavam-se dispostas segundo critérios estéticos que respeitavam certas regras e valores do campo literário $^{6}$. É importante, entretanto, analisar o autor e sua produção literária de outra(s) forma(s), dando ênfase à compreensão de seus escritos nos contextos de sua produção: buscando entende-los como documentos de estudo de uma dada realidade, de um dado evento ou de um sujeito que se inscreveu socialmente em determinado grupo e expôs, como letrado ou intelectual, seus interesses individuais ou coletivos.

Alguns trabalhos nessa direção foram empreendidos por importantes estudiosos da cultura ibérica. Dentre estes, destacam-se os estudos de historiadores espanhóis como Marcelino Menéndez y Pelaio, Celestino Pujol y Camps e Joan Estruch Tobella, e aqueles de portugueses como Maria Tereza Amado e Antônio de Oliveira. Os estudos já datados de Marcelino Menéndez y Pelaio ${ }^{7}$ e de Celestino Pujol y Camps $^{8}$, por um lado, apontaram para a importância literária e poética do escritor português sem deixar de salientar os problemas concernentes ao uso de um método historiográfico, como fizeram Saraiva e Lopes. Para esses estudiosos, antes de qualquer coisa, D. Francisco Manuel de Melo se comportaria como um político-historiador do século XVII, como muitos escritores de sua época, que se serviram do discurso histórico para a formação política do príncipe, seguindo o modelo da Historia Magistrae Vitae ciceroniano, e para a propaganda política. Isto posto, apesar desses estudiosos compreenderem e reforçarem o aspecto estético da obra de Melo, eles não deixaram de sublinhar a importância desse bel-letrismo na construção e estruturação de elementos importantes - políticos - das sociedades barrocas da península ibérica da época moderna, ao contrário dos autores do manual de literatura portuguesa anteriormente mencionado. 
Daí que esses estudiosos trataram os escritos de Melo com certa desconfiança: por serem eivados de comentários políticos e muito marcados por certa subjetividade estilística, aqueles escritos eram, portanto, desvalorizados e desaconselhados de serem empregados como documentos históricos, mas não como documentos ou testemunhos de uma mentalidade política da época.

Por outro lado, Joan Estruch Tobella, interessado no uso dos escritos de Melo para o estudo da história catalã, buscou analisá-los mais criticamente mostrando que, apesar de alguns deslizes e falsificações de informações e apesar da forte presença de comentários e juízos políticos ao longo das descrições históricas, a obra do fidalgo apresentava certo caráter crítico que deveria ser salientado. E, diante disso, seus escritos poderiam também ser empregados, mediante a crítica necessária, como documentos ou fontes de época para o estudo da história catalã, e mais precisamente do levante de $1640^{9}$.

Entre os estudiosos portugueses, Maria Tereza Amado, na senda crítica de Tobella, ressaltava a novidade instrumental e metódica da historiografia do fidalgo, apontando para o fato de que, apesar de seus escritos se assemelharem àqueles dos políticos-historiadores do século XVII, como deixavam ver os estudiosos tradicionais, a escrita histórica de Melo trazia fortes características críticas que permitiriam classifica-lo, de forma diversa do que até então se fazia. A leitura de Amado tinha por característica a tentativa de classificar a pratica discursiva do diplomata português na categoria de um pensamento historiográfico crítico avant la lettre ${ }^{10}$.

Com ela, o historiador coimbrão Antônio de Oliveira, mais preocupado com o caráter histórico dos escritos de Melo e com o uso documental que o historiador hodierno poderia fazer de suas obras para a análise de muitos processos políticos vividos em Portugal no século XVII, explorava essas afirmações e leituras de Tobella e Amado. Ele buscava ressaltar que, como os dois historiadores costumavam dizer, apesar dos muitos deslizes e falsificações históricas empreendidas pelo fidalgo, a obra de Melo possuiria um grande valor informativo para os historiadores e, como quis o próprio fidalgo, não deveria ser esquecida ${ }^{11}$.

Assim sendo, de modo geral, os estudos sobre os escritos históricos de Francisco Manuel de Melo, que inicialmente elaboraram-se no interior do campo da literatura, foram, paulatinamente, apropriados por historiadores catalães e portugueses que buscaram compreender mais criticamente - historicamente - seu lugar social de produção. E, na sequência, reabilitar o uso dos escritos do fidalgo como importantes documentos históricos. Esses estudos, como muitos empreendidos contemporaneamente, buscaram estabelecer uma 
compreensão da historiografia do fidalgo com base no estudo direto de seus escritos históricos estabelecendo, com isso, uma classificação ou tipologia de sua produção com base em critérios e categorias produzidas fora do ambiente cultural do aristocrata português.

Diante desse quadro analítico, pretendemos contribuir para esta reflexão analisando o pensamento histórico do fidalgo português não com base no estudo de seus escritos históricos - os quais, como dissemos, já foram amplamente estudados pela crítica historiográfica e literária mais recente -, mas com base em sua reflexão teórica sobre a escrita da história, reflexão essa travada fora do âmbito historiográfico.

O fidalgo Francisco Manuel de Melo escreveu, em 1657, o opúsculo Hospital das Letras, obra de crítica literária que narra a entrada de livros - tidos como personagens vivos e falantes - de autores reconhecidos na época em um hospital onde muitas obras de diversos gêneros e autores achavam-se adoentadas em consequência das críticas a elas feitas pelos comentaristas mais recentes. Nesta fantasia livresca, obra de retórica e eloquência, Melo elaborava uma reflexão sobre a natureza do discurso histórico numa obra de crítica: uma reflexão feita, portanto, fora de sua produção historiográfica. O que nos permite compreender, com os termos e conceitos do autor, como ele próprio compreendeu o fazer historiográfico de seu tempo e a sua própria escrita do passado.

O estudo das reflexões sobre a historiografia travados fora da escrita da história foram privilegiados pelos estudiosos italianos e, em especial, por Luciano Canfora que em sua obra Teorie e tecnica della storiografia classica estuda alguns tratados teóricos de historiografia da época antiga. A proposta de Canfora visava estabelecer uma compreensão do pensamento historiográfico clássico levando em conta categorias produzidas naqueles contextos precisos, sem corromper a reflexão com categorias externas, o que outorga à análise uma compreensão mais conjuntural e interna, e menos anacrônica, do problema.

Pretendemos assim analisar a teoria do discurso histórico de Francisco Manuel de Melo a partir da análise de uma breve reflexão por ele levantada no livro de crítica poética e retórica, o Hospital das Letras - livro contido na obra póstuma Apólogos dialogais publicada em 1721 - e, com base nisso, observar como o personagem, ele próprio, com ferramentas conceituais de seu tempo, definiu o que era o fazer histórico, de modo geral, e seu fazer histórico, de forma particular. Acreditarmos poder, assim, responder a algumas questões e problemas trazidos pelos estudiosos da cultura da época moderna portuguesa com base em recursos teóricos e conceituais forjados naquela ocasião particular. 


\section{O diálogo Hospital das Letras, obra de crítica poética, retórica, historiográfica e política}

O opúsculo Hospital das Letras, terminado no dia 10 de setembro de 1657 e dedicado ao professor de letras Daniel Pinário, de quem não temos nenhuma informação mais substantiva, é, como dissemos, uma obra de crítica literária. Escrita em forma de diálogo entre quatro livros que se comportam como personagens vivos e falantes, o opúsculo é uma obra de sátira e crítica da crítica literária da época moderna e serviu, além disso, para afirmar uma leitura mais subjetiva, ainda que teórica, do fidalgo português.

O cenário do diálogo é como uma enfermaria ou hospital onde o livro de Melo, os Apólogos dialogais, juntamente com o livro a Crítica de Justo Lípsio ${ }^{12}$, os Sueños de Francisco de Quevedo ${ }^{13}$ e os Ragguagli di Parnaso de Trajano Boccalini ${ }^{14}$ adentram, na qualidade de médicos, em um espaço onde jazem doentes os maiores expoentes da literatura portuguesa e europeia da época. Os autores dos livros-médicos que se tornaram personagens do escrito de Melo são famosos na época por suas letras e ideias, mas, sobretudo, são tidos como grandes críticos dos vícios e costumes da República através do uso de um pensamento de endereço estoico e tacitista. Já foi dito que Lípsio, em seus escritos, reabilitou o pensamento de Públio Cornélio Tácito por seu valor político e como uma alternativa a cultura e ao pensamento legado por Maquiavel, que naquela altura vinha proibido pela censura eclesiástica $^{15}$.

O papel destes livros-personagens no Hospital das Letras é o de reavaliar os comentários feitos a muitas obras literárias - entendendo o termo literário num sentido mais amplo, relativo não só às belas letras, mas também aos escritos políticos, históricos etc. - e de reabilitá-las na "República das Letras"16. Pelas palavras do próprio diálogo, podemos ver como se desenrolava a proposta do autor:

Autor. Saiu hoje por acordão da Relação de Apolo que vós, Senhor Trajano Bocalino, o Senhor Justo Lípsio, o Senhor D. Francisco de Quevedo e eu déssemos uma vista a este hospital, onde também jazemos como os mais pecadores; víssemos, ouvíssemos e remediássemos seus enfermos. Já não há para quem apelar, senão fazê-lo. (...)

Lípsio. Finalmente, senhor, nos quereis dizer que, por sermos os presentes todos quatro escritores de repreensões e emenda de vícios e costumes da República - eu com a minha Crítica, Bocalino com os seus Regaglios, Quevedo com os seus Sonhos, e vós com os Diálogos -, nos manda a Relação de Apolo, como rei da sabedoria, visitemos esta biblioteca convertida em hospital, ouçamos os doentes, nos informemos dos males e lhes consultemos o remédio? Difícil comissão nos é dada! ${ }^{17}$ 
Diante disso, os livros-doutores avaliariam as críticas feitas pelos contemporâneos àquelas obras, criticas essas que seriam a causa das doenças daqueles autores, e proporiam uma interpretação mais sã para a compreensão daquelas obras adoentadas, reestabelecendo assim a pretendida saúde das Letras. Cada livro-personagem tem um papel preciso no enredo do diálogo: o livro de Melo apresenta-se como o expositor dos médicos e dos doentes ${ }^{18}$, os livros de Quevedo e Boccalini apresentam-se como aqueles que iniciam o tratamento das “doenças" levantadas pelo autor, mas são, finalmente, atestados, ou não, pelo julgamento decisivo da Crítica de Justo Lípsio, interlocutor privilegiado e o personagem cujo juízo tem maior peso no diálogo. O que já de antemão demonstra a filiação de Melo à mundividência lipsiana.

O livro é dividido em dois momentos de crítica às obras literárias. Primeiramente, os livros-críticos medicarão as obras poéticas, em verso e em prosa ${ }^{19}$, e, então, finalmente, as obras politicas ${ }^{20}$.

Não há, aparentemente, um lugar de destaque nesse arranjo crítico para a escrita da história como uma disciplina ou mesmo gênero autônomo. A historiografia ora é apresentada como desdobramento de um gênero retórico ora como um desdobramento do discurso e pensamento político. Isso se dá na distinção feita pelo autor entre uma certa historiografia mais rigorosa e crítica, ilustrada pelos trabalhos do historiador romano Tito Lívio, e uma certa historiografia, que apesar de criteriosa, daria lugar à exposição de reflexões, juízos e discursos políticos. Este segundo modelo historiográfico proposto por Melo seria ilustrado pelos trabalhos de outro historiador romano, o já mencionado Públio Cornélio Tácito, objeto de reflexões e estudos do pensador flamengo, Justo Lípsio.

Contudo, apesar dessa ambiguidade do discurso histórico na pena de Melo, o mesmo é disposto e analisado no interior da parte referente à crítica da crítica das obras políticas, o que já, de antemão, nos induz a conjecturar a estreita relação proposta pelo fidalgo entre escrita da história e escrita ou ação política. E a aparição da reflexão sobre a historiografia se dá exatamente no momento em que o intelectual português lista o referido Tácito entre os grandes políticos de seu tempo. Diante dessa menção, surge a seguinte pergunta: Pois como se conta o Tácito entre os políticos, se ele foi histórico? ${ }^{21}$

Esse impasse conceitual e impactante do ponto de vista da organização da cultura, mostra que Melo, apesar de pensar o conhecimento histórico de forma bastante rebuscada e detalhada, toma partido ao privilegiar uma compreensão do fazer do historiador mais como uma ferramenta do político do que como um produto de mera contemplação. Contudo, de 
modo a resolver o impasse e para melhor ilustrar a corrente ou escola da qual se vê partícipe, Melo elabora uma reflexão teórica e crítica sobre as múltiplas possibilidades de se escrever história em sua época. É nessa reflexão que fica patente, no interior do pensamento do fidalgo, as diferentes categorias e os diferentes conceitos usados na época para pensar o discurso do historiador.

\section{A teoria do discurso histórico no pensamento de Francisco Manuel de Melo}

A reflexão teórica de Melo sobre a historiografia se faz na sequência de um debate reflexivo sobre o pensamento político ibérico que, parece-nos, tem estreita relação com esta reflexão historiográfica, a organiza. Ao discutir o caráter político do discurso histórico do historiador romano Públio Cornélio Tácito, como dissemos, Melo destaca a estreita relação, em seu modo de pensar a escrita da história, entre história e política ou, ainda, entre política e história. O livro-personagem de Melo inicia a reflexão sobre a historiografia política de Tácito da seguinte forma: "Autor. Dai, senhores, lugar aos doentes suspiros do patriarca dos estadistas, Cornélio Tácito." 22

Diante dessa afirmação, Melo enaltecerá o renascer moderno do pensamento e dos escritos do político e historiador romano, afirmando que depois da queda do Império Romano o Tácito ficara muitos anos sem ser lembrado - Reparei já muito em que, sendo o Tácito tão antigo, não florescesse sua memória nos séculos passados ${ }^{23}$-, além de enaltecer um ressuscitar de certa Escola de Tácito como fruto de uma providência divina nos tempos modernos. Dirá ele:

Autor. Deixai-me que crea antes fora providência altíssima relevar-nos tantos anos de uso de suas máximas; mas porque do mesmo modo que se afirma da antiga Roma, que por alimpar a república tornou a admitir os médicos, em razão da muita gente que sem eles vivia e multiplicava os trezentos anos de seu desterro, segundo quer Dioniso de Halicarnase, assim também parece que, por castigar a República com os efeitos de máximas rigorosas e insuportáveis alvitres, permitiu Deus ressuscitasse a escola de Tácito e visse a gente suas obras, para ser castigada na observância de seus escritos. ${ }^{24}$

Providência que, segundo o autor, se deu pela indústria de alguns estudiosos como Cipião Amirato ${ }^{25}$, Sebastião Querino, Alexandre Sansovino, D. Baltasar de Flávios ${ }^{26}$, D. Carlos Colona $^{27}$, Manuel Sueiro ${ }^{28}$ e outros que tomaram o Tácito à sua conta, traduzindo-o, anotando-o e ilustrando-o ${ }^{29}$. Esse "resgate" da obra do romano baseava-se, como explicitava o próprio Melo, no estudo de três únicas obras do autor clássico, a saber, a História de Roma, os Anais e o Júlio Agricola ${ }^{30}$. Esse movimento seria, para o sábio fidalgo, o elemento 
propulsor de um retorno daquela cultura e a fonte de onde ele próprio teria bebido para se inspirar e poder propalar a orientação do sábio politico romano. Esse lugar cultural do português, que o colocava em estreita relação com o reviver da cultura clássica, o inseria no movimento, mais vasto, do humanismo europeu.

A ambiguidade já assinalada entre a produção histórica e política do escritor romano era resolvida pela Crítica de Lípsio através de uma reflexão sobre o modo como o discurso político vinha organizado ao longo dos relatos, sobre o modo como as prescrições se estruturavam diante das descrições. O livro de Lípsio respondia ao impasse ou confusão entre o discurso histórico e o político com a seguinte solução:

\begin{abstract}
Autor. Pois como se conta o Tácito entre os políticos, se ele foi histórico? (...) Lípsio. A pergunta é tão formal, que requeria mais tempo para vos satisfazer; porém, para o ficardes por agora, bastará advirtirdes que neste autor, como nos mais historiadores, não serve o discurso ao caso; antes o caso serve ao discurso, sendo contado como acaso tudo que se conta. É bem verdade que a História se quer vestida e revestida de juízos, sentenças, secretos, malícias e discrições; porque, enfim, uma História nua, sobre desonesta, é desaproveitada. Isso vos diria Agostinho Mascardi, que melhor o escreveu do que o observou, mas contudo não por tal modo que se quebre o fio dos acontecimentos, sendo tirado fortemente para outra parte pela força do discurso. ${ }^{31}$
\end{abstract}

Assim sendo, a ambiguidade da produção literária de Tácito residia no modo como este, segundo Melo, organizava a relação de dependência entre o caso, ou os indícios e fatos gerados a partir dos mesmos indícios, e o discurso, ou seja, a reflexão ética e política surgida a partir da reflexão direta sobre os acontecimentos históricos. O que já fazia notar a característica fortemente pragmática do pensamento político do pensador romano.

Na verdade, para além de explicar a natureza da historiografia política de Tácito, ou de sua política eminentemente prática, vivida, como diriam os teóricos de hoje, como uma Realpolitik, as possibilidades de relação vertical entre os conceitos lançados por Melo, a saber, o caso e o discurso, resultavam na possibilidade de organização de duas formas precisas de se fazer ou escrever a história na época.

A primeira delas, como dissemos, onde o caso é servo do discurso, caracterizaria uma historiografia, aquela tacitista, onde a história é ou serve como instrumento da formação e da prática do político. Donde, por ser importante na formação do mesmo, o historiador não deve, na maioria das vezes, inventar casos, indícios e fatos, antes deve tentar organiza-los em função da lógica do fazer e do pensar políticos.

A escrita da história de Tácito, assim como aquela dos tacitistas modernos, era uma escrita, na verdade, política que entremeava narrativa dos acontecimentos com juízos e 
leituras sobre a ação política. A história tacitista, como aquela de Melo, seria, portanto, uma história útil e não unicamente uma história crítica, apesar do que já disseram Tobella e Amado. Seria também um veículo de teorias, reflexões, pensamentos, juízos e discursos políticos.

Por outro lado, surge desse raciocínio, a reflexão sobre uma outra escola historiográfica onde, ao contrário, o discurso é servo do caso ou, mesmo, onde o discurso se apresentaria como algo de pouca relevância na escrita do historiador. Essa outra vertente da historiografia da época era classificada por Melo como a Escola de Tito Lívio. Essa corrente historiográfica daria mais importância à narrativa do caso legando pouco espaço ao seu uso político. Seria, portanto, uma historiografia mais contemplativa da verdade - ou verossimilhança - dos acontecimentos e serviria como um elemento do conhecimento puro. $\mathrm{O}$ produto dessa escola, podemos inferir, não apresentaria frutos para a vida ativa, antes teria consequências somente no plano do conhecimento contemplativo.

A oposição, portanto, entre a história-útil, ativa, e a história-crítica, contemplativa, era posta dessa forma no dialogo de Melo pela fala do livro de Lípsio:

\begin{abstract}
Lípsio. Em uma de duas maneiras se deve escrever a História. A primeira quiseram os antigos fosse austera e incorrupta, sem que o historiador pusesse de sua casa mais que o estilo, do qual modo de historiar foi grande observante Tito Lívio, que aqui vedes, e entre os gregos o famoso Tucídides, principal texto desta faculdade; a segunda não só consente, mas requere no historiador que entreponha seu juízo, quando refere as acções, e sobre elas levante discursos, como não sejam alheios ou prolixos. Destes foi ilustre sequaz o Tácito, tomando-o já de Xenofonte e outros primeiros historiadores e políticos. A classe dos romanos se dividiu em parciais sentimentos, julgando uns que a História se havia de escrever pura, outros ornada, assim depois os vulgares italianos, belgas, espanhóis e franceses. ${ }^{32}$
\end{abstract}

Assim, com base nas palavras do diálogo, a diferença entre a escrita da história titoliviana e aquela tacitista residiria no fato de que a primeira almejaria sobretudo a pureza do relato, sendo este discurso, portanto, um derivado da arte do estilo, da retórica - é certo que uma retórica preocupada com a busca e a aquisição mais criteriosa da verdade ou verossimilhança - e a segunda almejaria, através dos relatos históricos, lançar juízos e discursos de modo a, como dissemos, formar príncipes e intervir na opinião pública ${ }^{33}$. O lugar desse outro modelo oriundo de Tácito estaria situado não no interior da cultura da eloquência, da Retórica, mas, antes de qualquer coisa, no interior da escrita política. Os tacitistas escreviam livros de reflexão política ao escrever livros de história. Prescreve-se que, apesar do historiador dever preocupar-se com o rigor das informações históricas, este buscaria 
empregar o relato de modo a dispor uma reflexão política, prática e útil, entrepondo juízos e discursos ao longo do relato, salpicando a narrativa pura com reflexões úteis à ação.

Para além destas diferenças colocadas entre as duas escolas, sobressai do pensamento de Melo o fato de que cada um desses paradigmas historiográficos produziriam tipos ou gêneros de escrita peculiares. Como expõe mais uma vez o livro de Lípsio:

\begin{abstract}
Agora, se me perguntares meu parecer nesta confusão de opiniões, dir-vos-ei que os analistas, crónicos, sumaristas, epitomistas e epilogistas, como todos aqueles que escrevem e regulam sucessos humanos segundo a ordem dos tempos, não tem outra autoridade e jurisdição, mais que para referi-los ordenados, ajustando-se à verdade das cousas e cômputo dos dias; mas aqueles historiógrafos que se empregam na escritura de uma só acção, como se disséssemos a vida de um príncipe, o sucesso de uma guerra, a relação dos movimentos e transferência de uma república, a estes tais afirmo ser lícito e obrigatório salpicar de sentenças, observações e juízos a sua História, porém com tal siso e mesura, que não seja o esmalte mais que o ouro, sob pena de degenerarem de historiadores a discursantes. A razão é clara, porque aqueles que escrevem histórias gerais, como Barônio, Eusébio, Piñeda, Tarcagnota, Carrilho e outros semelhantes, com a grande variedade de matérias que nos oferecem e trazem à memória nos ensinam e deleitam, que são os dous honestos fins de toda a lição boa; mas aqueles que só pintam uma acção particular, como nela não possam concorrer as cópias da variedade e estranheza de inventos, que as primeiras Histórias compreendem, é necessário que o que faltou de riqueza à narração supra a erudição em nosso proveito. ${ }^{34}$
\end{abstract}

Assim, para além do que já foi dito, a diferença entre as duas escolas organizadas na reflexão de Melo, residiria também no tipo ou estilo da escrita histórica: seguidores de Tito Lívio escreveriam Análises, Crônicas, Sumários, Epítomes e Epílogos, ao passo que os de Tácito produziriam Relatos, Relações, narrativas de eventos precisos, biografias e outros escritos falando de coisas mais precisas e circunscritas, como as próprias epanáforas de Melo anteriormente mencionadas. Isto porque, a especificidade do relato permitiria àquele tipo de historiador-político gastar tempo maior com reflexão de natureza ética e política.

\begin{tabular}{|l|l|}
\hline Escola de Tito Lívio/Tucídides & Escola de Tácito/Xenofonte \\
\hline “Austera e incorrupta" & Presença de "Juízos" e "Discursos" \\
\hline Preponderância do Estilo & Preponderância do Discurso \\
\hline Pura (Contemplação) & Ornada (Ação) \\
\hline Análises, Crônicas, Sumários, Epítomes e Epílogos. & $\begin{array}{l}\text { Relatos, relação, narrativas de eventos precisos, } \\
\text { biografias. }\end{array}$ \\
\hline
\end{tabular}

Tabela 1. Diferenças entre as escolas historiográficas como propostas por Francisco Manuel de Melo. 
Diante do dito, podemos estabelecer, com base nas categorias lançadas pelo próprio Melo, a seguinte organização das escolas ou modelos historiográficos da época moderna em Portugal, como se acha disposto na tabela abaixo.

A distinção feita entre um modelo histográfico mais contemplativo, mais preocupado com a busca pura pela verdade ou, ao menos, pela verossimilhança nos indícios históricos e outro modelo historiográfico mais ativo, que apesar de não negligenciar essa busca, salpicaria os relatos com juízos e discursos, está, antes de qualquer coisa, na presença e projeção do discurso político e não na negligência com a análise histórica. A relação específica de domínio ou subordinação entre Caso e Discurso, como dissemos, é a chave lançada por Melo para caracterizar cada um desses modelos historiográficos: quando o discurso é servo do caso, a historiografia é a da Escola de Tito Lívio, quando, ao contrário, o caso é servo do discurso, como afirmou Melo em trecho já mencionado, a historiografia pertence à Escola de Tácito.

Os representantes do modelo historiográfico (ou político) tacitista mencionados por Francisco Manuel de Melo estão dispostos na tabela abaixo:

\begin{tabular}{|c|}
\hline Escola de Tácito \\
\hline Sebastião Querino \\
\hline Alexandre Sansovino \\
\hline D. Baltasar de Flávios \\
\hline D. Diogo de Mendonça \\
\hline D. Lourenço Val de Lameno \\
\hline Gabriel Altingen. \\
\hline D. Francisco de Lanario y Aragón, Duque de Carpiñano \\
\hline João de Barros (1496-1570) \\
\hline Cipião Amirato (Scipione Ammirato) (1531-1601) \\
\hline Diogo do Couto (1542-1616) \\
\hline Justo Lípsio (1547-1606 ) \\
\hline Trajano Boccalini (1556-1613) \\
\hline Bartolomeu Leonardo de Argensola (1562-1631) \\
\hline D. Carlos Coloma de Sá (1567-1637) \\
\hline D. Antonio de FuenMayor (1569-1599) \\
\hline Famiano Strada (1572-1649) \\
\hline Cardeal Guido Bentivoglio (1577-1644) \\
\hline Manuel Sueiro (1580-1629) \\
\hline Francisco de Quevedo (1580-1645) \\
\hline D. Juan Antonio de Vera y Figueiroa (1583-1658) \\
\hline René de Ceriziers (1603-1662) \\
\hline Francisco Manuel de Melo (1606-1666) \\
\hline
\end{tabular}

Tabela 2. Elenco de intelectuais - historiadores e políticos - da Escola de Tácito mencionados por Francisco Manuel de Melo no Hospital das Letras. 
Da mesma forma, aqueles da Escola de Tito Lívio, antigos e modernos, mencionados pelo crítico, acham-se dispostos na tabela seguinte:

\begin{tabular}{|c|}
\hline Escola de Tito Lívio \\
\hline Cipião de Pluis Benter \\
\hline Diogo Beldu \\
\hline Blau Brito \\
\hline Frei Marcos de Guadalajara \\
\hline Antonio de Castilho \\
\hline Beroso caldeu (Século III a.C.) \\
\hline Dionisio Halicarnaso (Século I a.C.) \\
\hline Aufídio Bássio (-65 d.C.) \\
\hline Diodoro Siculo (90 a.C.-30 a.C.) \\
\hline Dião Cássio (ca. 155-229) \\
\hline Eusébio de Cesareia (265-339) \\
\hline Teodoro, o leitor e a história tripartita (Século VI) \\
\hline Eneas Silvio Piccolomini (1405-1464) \\
\hline Bartolomeu Sacchi ou Platina (1421-1481) \\
\hline Marco Antonio Sabellico (1436-1506). \\
\hline João Ânio de Viterbo (1437-1502) \\
\hline Marco Marulo (1450-1524) \\
\hline Polidoro Virgilio (1470-1555) \\
\hline Francesco Guicciardini (1483-1540) \\
\hline Giovanni Tarcagnota (1490-1566) \\
\hline Giovanni Baptista Adriani (1511-1574) \\
\hline Jerónimo Zurita (1512-1580) \\
\hline Juan de Pineda (1513-1593) \\
\hline Luís del Mármol Carvajal (1520-1600) \\
\hline Gonçalo de Ilhescas (1521-1574) \\
\hline Esteban de Garibay (1533-1600) \\
\hline Antonio Possevino (1533-1611) \\
\hline Juan de Mariana (1536-1624) \\
\hline César Barônio (1538-1607) \\
\hline Orazio Torsellini (1545-1599) \\
\hline Antônio de Herrera y Tordesilhas (1549-1626) \\
\hline Martim Carrilho (Séculos XVI-XVII) \\
\hline Luis de Bavia (1555-1628) \\
\hline Enrico Caterino Davila (1576-1631) \\
\hline António Brandão (1584-1637) \\
\hline Manuel de Faria e Sousa (1590-1649) \\
\hline Virgilio Malvezzi (1595-1654) \\
\hline Luís Cabrera de Córdoba (1599-1623) \\
\hline Ferdinando Bardi (século XVII) \\
\hline
\end{tabular}

Tabela 3. Elenco de historiadores da Escola de Tito Lívio mencionados por Francisco Manuel de Melo no Hospital das Letras. 
Uma vez a distinção feita entre as duas correntes, é preciso lembrar que, apesar da ênfase na importância do uso prático e político do discurso histórico, os historiadores ou políticos tacitistas não costumavam "jogar o bebê fora junto com a água do banho": investiam na importância de salpicar a narrativa dos acontecimentos com juízos e discursos, de misturar a escrita dos eventos com leituras e mundividências políticas, com tal siso e mesura, que não seja o esmalte mais que o ouro, sob pena de degenerarem de historiadores a discursantes ${ }^{36}$. A verdade não era aqui distorcida em nome da intervenção política, ela era somente organizada por uma lógica ou princípio mais prático, ativo.

Assim, para os historiadores-políticos, havia certa preocupação com a narração dos eventos históricos: o que mostra que a teoria historiográfica de Melo, apesar de subordinar a análise histórica ao pensamento político, não abre mão do fato de que os políticoshistoriadores não devem deixar de se preocupar com a Descrição, ainda que esta seja tomada como palco de reflexões e Prescrições. O que confirma as análises feitas por Tobella, Amado e Oliveira acerca da historiografia de Melo, que apesar de ser floreada por juízos e discursos não deixa de trazer informações verossímeis sobre os eventos descritos. E, por conta disso, as obras de Melo podem sim ser usadas como documentos primários ou fontes contendo informações valiosas a respeito dos eventos narrados.

Na verdade, a preocupação mesma da Escola Tacitista, ou mesmo de Melo, em propor uma narrativa historiográfica mais circunscrita e pontual já demonstra o interesse de tirar da responsabilidade do escritor o extremo rigor da pesquisa sem deixar de responsabiliza-lo pela verossimilhança dos eventos narrados. A diferença entre uma historiografia e outra, nos parece, não reside num descompromisso com a busca pela verdade ou verossimilhança, mas sim num acento na importância contemplativa ou ativa da produção do historiador.

\section{Conclusão}

As conclusões da análise da teoria do discurso histórico de D. Francisco Manuel de Melo são convergentes com aquelas análises feitas com base nos escritos históricos de Melo por Estruch Tobella, Tereza Amado e António Oliveira: o fidalgo Francisco Manuel de Melo, apesar de dar enorme importância ao salpicar de juízos e discursos em sua historiografia propôs, na teoria ao menos, que o historiador buscasse sempre manter-se fiel ao real, ao verdadeiro, ou senão, pelo menos, ao verossímil, de modo que não seja o esmalte mais que o ouro e de modo que os historiadores não se degenerassem em discursantes. 
Diante disso, podemos dizer que a historiografia de Melo, apesar de comportar-se também como um veículo de teses e reflexões políticas, de juízos e discursos, não deixava de preocupar-se com a verdade e de trazer para os seus leitores informações importantes para a compreensão dos contextos estudados e empregados na sua reflexão política. Podemos, inclusive, dizer mais: a narrativa de Melo é repositório de importantes indícios históricos, serve de documento aos estudiosos da história ibérica, mas é também repositório de importantes elementos de leitura política, serve de documento aos estudiosos do pensamento político português da época moderna.

Eugenio Garin, na obra Umanesimo italiano, fala de um momento na história do humanismo em que a retórica ia, pouco a pouco, divorciando-se da sua relação com a realidade, com a concretezza umana, estabelecida pelo próprio humanismo dos primeiros tempos. Diante disso, Garin expunha o desconforto de Pico della Mirandola com tal divórcio e a sua importante crítica à retórica ornada e vazia ${ }^{37}$. Diante desse processo, desse distanciamento entre saber e fala, entre sapiência e eloquência na época de Pico, o grupo do qual fazem parte os tacitistas do XVII, e com eles Sforza Pallavicino, Famiano Strada e Agostinho Mascardi, apesar de atribuírem importância ao salpicar de discursos e juízos políticos na narrativa, como dissemos com o caso de Melo, buscou em seus escritos teóricos e históricos reestabelecer a aproximação entre o conhecimento e a linguagem, tratar o discurso na sua relação com o conhecimento do real e não mais como simples ornamento ${ }^{38}$. E a própria distinção entre caso e discurso em Melo, como entre os críticos mencionados, já é prova de uma consciência dessa distinção e da necessidade da aproximação de ambos os aspectos: nas duas escolas históricas mencionadas pelo fidalgo o caso está sempre presente na equação.

Isto dito, podemos afirmar que a cultura produzida pelo fidalgo português se dispõe como um contínuo da tradição humanista iniciada na Itália nos primeiros tempos do século XIV. Na verdade, a proposta mesmo de reduzir o espectro analítico do historiador e usar o estudo do contexto para a formação do ator político, ainda que esse estudo comportasse também invenções e projeções da realidade histórica como formas mesmas de atuação e intervenção política, mostram que, o tacitismo se manteve fiel ao ideal humanista da busca e aproximação da verdade. Donde, os ornamentos, o esmalte de Melo, apesar de ornar a verdade histórica, o mencionado ouro, não excluía do discurso da historiografia tacitista e daquela de Francisco Manuel de Melo a preocupação com a verossimilhança e com o uso crítico da documentação primária. 
Os escritos históricos de Francisco Manuel de Melo podem, portanto, ser estudados como importantes elementos de análise histórica, como fontes de época para o estudo de temas como a Revolta da Catalunha de 1640, o Levante popular de Évora de 1637, a Restauração de Pernambuco de 1654, a vida do rei D. João IV e muitos outros temas de grande interesse para a historiografia ibérica, portuguesa, espanhola e mesmo a brasileira. E podem também ser estudados como veículos de teorias e discursos políticos proferidos pelo personagem português nos contextos em que ele se dispôs como um interventor. Isto porque, como o próprio Melo nos faz ver, não há distinção alguma entre um historiador e um político tacitista: os políticos tacitistas servem-se de histórias conjunturais para expor seus pensamentos e, por sua vez, os historiadores da mesma escola escrevem relatos para salpicálos de juízos e discursos políticos. Historiador e Político são pleonasmos no interior do pensamento tacitista da época moderna.

\section{Notas}

${ }^{1}$ SARAIVA, António Jose e LOPES, Oscar. História da literatura portuguesa. $7^{\circ}$ edição. Santos: Livraria Martins Fontes, 1973, pp. 489, 491-492.

${ }^{2}$ SARAIVA, Op. Cit., p. 506.

${ }^{3}$ Sobre o desenvolvimento da diplomática e de uma crítica historiográfica no período moderno, cf. POMIAN, Krzysztof. Sur l'histoire. Paris: Gallimard, 1999.

${ }^{4}$ GINZBURG, Carlo. "Sobre Aristóteles e a história, mais uma vez". In: Relações de força. São Paulo: Companhia das Letras, 2002, pp. 47-63.

${ }^{5}$ Essa perspectiva assaz tradicional e conservadora acerca da atuação política das classes populares, que permaneceu em vigor até meados do século XIX, e mesmo no olhar de alguns historiadores do século XX, foi reavaliada e criticada nos trabalhos de E. P. Thompson. Cf. especialmente: THOMPSON, E. P. "A economia moral da multidão inglesa no século XVIII". In: Costumes em comum. São Paulo: Companhia das Letras, 1998, pp. $150-202$.

${ }^{6}$ Um grande exemplo desta afirmação está contido na edição contemporânea das cartas de D. Francisco Manuel de Melo, editadas por Maria da Conceição Morais Sarmento, onde as cartas são organizadas com base na compreensão, assaz técnica, da produção de Melo como produto do esforço estilístico que vale o estudo. Em outras palavras, o critério de organização das cartas do fidalgo somente leva em consideração a importância da leitura das mesmas para o estudo da escrita do fidalgo, seu estilo e sua técnica literária. Não há nessas edições uma preocupação de ajuntar, colher e organizar as cartas do fidalgo de modo a entender esses documentos como indícios da participação e atuação do personagem em eventos e conjunturas políticas, sociais ou econômicas. Por isso, nessa edição somente publicou-se as cartas escritas por Melo e não aquelas recebidas por ele. Isso coloca para o historiador o problema da coleta histórica de documentos que, apesar de tidos como expoentes da bela escrita, são indícios de relações culturais e políticas de personagens envolvidos em conjunturas e processos históricos de relevo. Cf. MELO, Francisco Manuel de. Cartas familiares. Lisboa: Imprensa Nacional - Casa da Moeda, 1981.

${ }^{7}$ MENÉNDEZ Y PELAIO, Marcelino. "La historia considerada como obra artística" In: Obras Completas, Vol. VII - Estudios y discursos de crítica histórica y literária. Santander: Aldus, S.A. de Artes Gráficas, 1942.

${ }^{8}$ PUJOL Y CAMPS, Celestino. Melo y la revolución de Cataluña en 1640. Discursos leídos ante la Real Academia de la Historia en la recepción pública de D. Celestino Pujol y Camps el día 18 de Abril de 1886, Madrid, Imprenta y Fundación de Manuel Tello, 1886.

${ }^{9}$ Cf. TOBELLA, Joan Estruch. «Introducción» à sua edição de Historia de los movimientos, separacion y guerra de Cataluña. Madri: Editorial Castalia, 1996; Idem. «Las fuentes de Guerra de Cataluña, de Francisco Manuel de Melo», Criticón, 44, (1988), 7-24. 
${ }^{10}$ AMADO, Maria Tereza. “O pensamento histórico de Francisco Manuel de Melo.” In: Revista Penélope, n. 9/10, 1993, pp. 189-195.

11 OLIVEIRA, Antônio de. "D. Francisco Manuel de Melo, historiador". In: Península. Revista de Estudos Ibéricos. N. 6, 2009, pp. 17-60.

$12 \mathrm{O}$ livro a que se refere Melo em seu diálogo é provavelmente a Opera omnia quae ad criticam proprie spectant publicada em Leida em 1596.

${ }^{13}$ A obra em questão é o Sueños y discursos de verdades descubridoras de abusos, vícios y engaños, en todos los ofícios y Estados del Mundo. Barcelona: Estevan Libreros, 1627.

${ }^{14}$ Trata-se do De' Ragguagli di Parnaso, em três centúrias, as duas primeiras publicadas em Veneza, appresso Pietro Farri em 1612 e a terceira em 1615.

${ }^{15}$ Como afirmou Antônio de Oliveira: No desenvolvimento da contra-reforma política, e sobretudo depois de Maquiavel ter sido colocado no Índice, em 1559, o historiador Tácito transforma-se então em político, como se encontra explicado no Hospital das Letras ou no Epítome de Manuel Faria e Sousa, em texto muito paralelo, tornando-se, para Justo Lípsio (1547-1606), uma «alternativa do Florentino, seu par ou sucedâneo», na expressão de Martim de Albuquerque, tendo-o temperado através da doutrina do neoestoicismo. (OLIVEIRA, 2009, p. 35).

16 Espaço virtual de afirmação e memória dos grandes escritos na época moderna: lugar também de enaltecimento e lembrança dos esforços de grandes escritores e intelectuais. Apresentava-se como um lugar imaginário para onde iriam os livros dignos de lembrança, mas que excluía e marginalizava aquelas obras e autores tidos por indignos através de um mecanismo gerador de esquecimento.

${ }^{17}$ MELO, Francisco Manuel de Melo. Hospital das Letras. Rio de Janeiro: Editorial Bruguera, s/d, pp. 9-10.

${ }^{18}$ Nas palavras do autor: Lípsio. (...) Façamos como bons servos; e, pois o hospital é do destino deste Reino, sejo o nosso Autor quem nos inculque e nos informe acerca dos que devem ser curados e dos que não tem cura. Idem, p. 10.

${ }^{19}$ Os livros doentes tratados pelos críticos amigos de Melo eram obras, impressas ou manuscritas, dos seguintes autores: Luís de Camões, Francisco de Sá de Miranda, Luís de Gôngora, Lope de Vega Cárpio, Lupércio Leonardo, D. Diogo de Mendonça, D. Afonso de Ercilla, António Ferreira, Messias March, Gregório Silvestre, D. Gabriel de Bocángel e Unçueta, Francisco Lopes de Zarate, Miguel da Silveira, Manuel de Faria e Sousa, Anastácio Pantaleão, D. Jerônimo Cancer, Salvador Jacinto Polo de Medina, Tomé de Burguillos, Alonso Jerónimo de Sala Bobadilha, D. Alonso de Castilho, D. António Solis, D. Romão Monteiro, D. António Martines, D. Antonio de Huerta, D. João Veles, Luis de Benavente, Luis Veles de Guevara, D. Antonio Coelho, D. Jerônimo Coelho, Gaspar de Belmonte, D. Gabriel de Quesada, D. Pedro Calderon, D. Francisco de Roxas, D. João de Orosco, D. Francisco Rolim, D. António de Mendonça, Diogo Bernardes, Francisco Rodrigues Lobo, Estêvão Rodrigues de Castro, Vasco Mouzinho de Quevedo, Gabriel Pereira de Castro, D. Francisco de Portugal, António Gomes de Oliveira, Francisco de Sousa Coutinho, Manuel Tomás, Fernão Correa de Lacerda, Nuno de Mendonça, Martim de Castro, Gaspar Mimoso, Luís Pereira, Simão Torresão, Álvaro Frade, Tomé Tavares, Diogo de Sousa, António de Castilho, Henrique Nunes, Francisco Correa, Gonçalo de Lucena, D. Tomás Jordão, Jorge da Câmara, Fernão Álvares do Oriente, Miguel Botelho, Sóror Violante do Céu, D. Bernarda, Diogo de Paiva e Francisco Manuel de Melo (o autor).

${ }^{20}$ Os livros de política medicados foram os seguintes: a Política de Justo Lípsio, a Política de Dios de Francisco de Quevedo, a História e os Anais de Cornélio Tácito, o Tácito francês de João Gaston, o Governador Cristão de Frei João Marques, a Política Cristã de Frei João de Santa Maria, a Filosofia moral de príncipes do padre João de Torres, a República segura de Frei Manuel do Espírito Santo, a Harmonia política de António de Sousa de Macedo, a Arte de Reinar de António Carvalho de Parada, o Espelho de príncipes de Francisco de Monroy, o Conselho e Conselheiro de D. Lourenço Ramires do Prado, o Conselheiro de príncipes de Bartolomeu Felipe, a Razão de Estado de Eugenio de Norbona, os Discursos políticos de Pedro Fernandes de Navarrette, a Política de Adão Contzem, a Política de Jacobo Simancas, a Razão de Estado de Bovadilha, D. Diogo de Saavedra Fajardo, a Política Angélica de António Henrique Gomes, etc.

${ }^{21}$ MELO, op. Cit., p. 103.

${ }^{22}$ Utilizamos para este estudo a seguinte edição da obra Hospital das Letras: MELO, Francisco Manuel de. Hospital das Letras. Rio de Janeiro: Editorial Bruguera, s/d, p. 101. O negrito é meu.

${ }^{23}$ MELO, s/d, p. 102.

${ }^{24}$ Idem, p. 102.

${ }^{25}$ Cipião Amirato. Historiador apuliense nascido em Lecce em 1531 e falecido em Florença em 1601. Autor de um Discorsi sopra Cornelio Tacito, Florença: 1594.

${ }^{26}$ Personagens não identificados.

${ }^{27}$ D. Carlos Coloma de Sá. Militar, diplomata e historiador espanhol nascido em Alicante em 1567 e falecido em Madri em 1637. Traduziu para o castelhano os Anais e as Historias de Tácito e os publicou em Duay em 1629. 


\footnotetext{
${ }^{28}$ Manuel Sueiro. Historiador português nascido em 1528 e falecido em 1629. Traduziu para o espanhol obras de Tácito [Las obras de C. Cornelio Tacito. Anvers: Beller, 1613].

${ }^{29} \mathrm{O}$ forte teor de uma lógica providencialista presente no pensamento do autor em questão achava-se muito difusa no discurso dos eclesiásticos portugueses da época e marcava uma tendência muito comum na lógica da época, inclusive naquela mais laica. Essa tendência é mencionada por Giuseppe Marcocci (2014) como um elemento importante no pensamento político e diplomático português do período moderno.

${ }^{30}$ Outros textos de Tácito, como a Germania, eram conhecidos à época e, muito provavelmente por alguns dos personagens elencados por Melo, como Justo Lípsio. Ibidem, p. 103.

${ }^{31}$ MELO, op. Cit., p. 103.

${ }^{32}$ MELO, s/d, p. 128-129.

${ }^{33}$ É curioso observar que na pluma de outro importante teórico do pensamento histórico da época moderna, Agostino Mascardi, a verdade vem posta e pensada como um fruto ou produto da fé pública. A verdade não existiria, portanto, a priori, mas dependeria do convencimento, da propaganda empreendida pelos intelectuais e escritores da época.

${ }^{34}$ MELO, s/d, p. 128-129.

${ }^{35}$ Não nos foi possível identificar alguns personagens mencionados pelo autor. Estes personagens, sem data de nascimento e morte acham-se dispostos nas tabelas antes daqueles de quem temos melhores informações.

${ }^{36}$ Idem, p. 128.

${ }^{37}$ La piú aperta denuncia di questo distacco è costituita appunto dalla lettera indirizzata nel 1485 a Ermolao Barbaro, de genere dicendi philosophorum, che costituisce un vero e proprio "manifesto" contro la degenerazione della retorica in cui riaffiorava perfino il deteriore nominalismo dei calculatores di Oxford. La nuova filologia nata come nuova filosofia, e cioè come coscienza critica della ricerca di una concretezza umana, si era estenuata in una scienza nominum opposta a una scienza rerum; nel culto di uma formalità vuota che non poteva non condurre a uno scetticismo larvato, e già si concretava in uma crise morale. GARIN, Eugenio. L'umanesimo italiano - Filosofia e vita civile nel Rinascimento. Bari: Laterza, 2004, p. 120.

${ }^{38}$ La risposta che alla questione dará lo Sforza Pallavicino nel Trattato dello stile, rifacendosi al Pico, ma utilizando le osservazioni che sulla maniera di scriver la storia avevano fatto Famiano Strada e Agostino Mascardi, è che, "essendo ufficio del filosofo la sincera manifestazione della verità nel suo semplicissimo aspetto, non conviene a lui alterare, o con l'ingrandimento la sembianza di lei, o col movimento la pupilla di chi la mira", Il che significa distinguere dal pensiero, non già la parola nella sua appropriatezza, ma l'ornato, la retorica ormai degenerata. Idem, pp. 121-122.
}

\section{Referências Bibliográficas}

ALBUQUERQUE, Martim de. Um percurso da construção ideológica do Estado. A recepção lipsiana em Portugal: estoicismo e prudência política, Lisboa, Quertzal, 2002;

AMADO, Maria Tereza. O pensamento histórico de Francisco Manuel de Melo. In: “Penélope". N. 9/10, Lisboa: Edições Cosmos, 1993;

ANACLETO, Marta Teixeira; AUGUSTO, Sara \& SANTOS, Zulmira (coords.). D. Francisco Manuel de Melo e o barroco peninsular. Coimbra: Imprensa da Universidade, 2010;

ARON, Raymond. Introduction à la philosophie de l'histoire - Essai sur les limites de l'objectivité historique. Paris: Gallimard, 1948;

CANFORA, Luciano. Teorie e técnica della storiografia classica. Bari: Laterza, 1996;

ELLIOT, John H. La España Imperial - 1469-1716. Barcelona: Editora Vicens-Vives, 1978;

FUETER, Edmond. Histoire de l'historiographie moderne. Paris: Librairie Félix Alcan, 1914;

GARIN, Eugenio. L'Umanesimo italiano. XXX

HARTOG, François. Memória de Ulisses - Narrativas sobre a fronteira na Grécia antiga. Belo Horizonte: Editora da UFMG, 2004; 
. O espelho de Heródoto - Ensaio sobre a representação do outro. Belo Horizonte: Editora da UFMG, 1999;

HESPANHA, António Manuel. As vésperas do Leviathan - Instituições e poder político em Portugal, século XVII. Lisboa: Almedina, 1994;

LEITE, Bruno Martins Boto. O caso servo do discurso - A "Escola de Tácito" e a historiografia de D. Francisco Manuel de Melo na Europa do XVII. Dissertação de Mestrado. PPGHIS/UFRJ, 2007;

MARCOCCI, Giuseppe. A consciência de um império. 2014;

MELO, Francisco Manuel de. Hospital das letras. Apólogo dialogal quarto. Rio de Janeiro: Editorial Bruguera, s/d;

MOUSNIER, Roland. XXXX!!!!!!

OLIVEIRA, António de. Dom Francisco Manuel de Melo, historiador. In: Península, Revista de estudos ibéricos. N. 6, 2009, pp. 17-60;

POMIAN, Krzysztof. Sur l'histoire. Paris: Gallimard, 1999;

PRESTAGE, Edgar. D. Francisco Manuel de Melo. Coimbra: Imprensa da Universidade, 1933;

. D. Francisco Manuel de Melo - um esboço biográfico. Lisboa: Fenda, 1996;

THOMPSON, E. P. Costumes em comum. São Paulo: Companhia das Letras, 1998. 